\title{
Aerodynamic Design of Heavy Vehicles Reporting Period September 2001 through January 15, 2002
}

R. McCallen, K. Salari, J. Ortega, D. Yen-Nakafuji T. Dunn, F. Browand, M. Hammache, A. Leonard, M. Rubel, W. Rutledge, C. Roy, M. McWherter-Payne, J. Ross, D. Satran, B. Storms, S. Walker, and J.T. Heineck

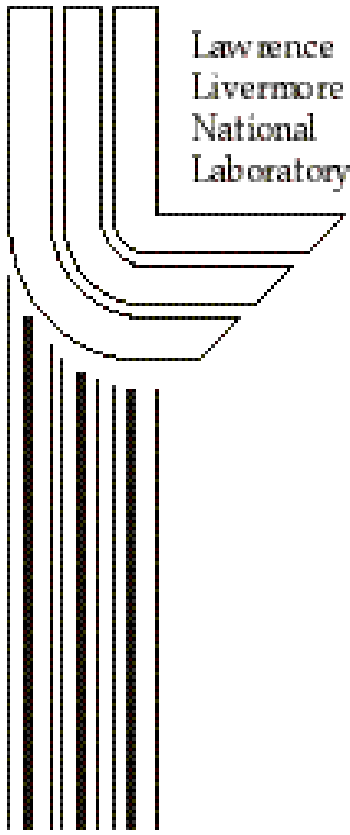

January 25, 2002 


\section{DISCLAIMER}

This document was prepared as an account of work sponsored by an agency of the United States Government. Neither the United States Government nor the University of California nor any of their employees, makes any warranty, express or implied, or assumes any legal liability or responsibility for the accuracy, completeness, or usefulness of any information, apparatus, product, or process disclosed, or represents that its use would not infringe privately owned rights. Reference herein to any specific commercial product, process, or service by trade name, trademark, manufacturer, or otherwise, does not necessarily constitute or imply its endorsement, recommendation, or favoring by the United States Government or the University of California. The views and opinions of authors expressed herein do not necessarily state or reflect those of the United States Government or the University of California, and shall not be used for advertising or product endorsement purposes.

This work was performed under the auspices of the U. S. Department of Energy by the University of California, Lawrence Livermore National Laboratory under Contract No. W-7405-Eng-48.

This report has been reproduced directly from the best available copy.

Available electronically at http://www.doc.gov/bridge

Available for a processing fee to U.S. Department of Energy

And its contractors in paper from

U.S. Department of Energy

Office of Scientific and Technical Information

P.O. Box 62

Oak Ridge, TN 37831-0062

Telephone: (865) 576-8401

Facsimile: (865) 576-5728

E-mail: reports@adonis.osti.gov

Available for the sale to the public from

U.S. Department of Commerce

National Technical Information Service

5285 Port Royal Road

Springfield, VA 22161

Telephone: (800) 553-6847

Facsimile: (703) 605-6900

E-mail: orders@ntis.fedworld.gov

Online ordering: http://www.ntis.gov/ordering.htm

OR

Lawrence Livermore National Laboratory

Technical Information Department's Digital Library

http://www.llnl.gov/tid/Library.html 


\section{Quarterly Report}

Reporting Period: September, 2001 through January 15, 2002

Project Title: $\quad$ Aerodynamic Design of Heavy Vehicles

Investigators: Rose McCallen, Kambiz Salari, Jason Ortega, Dora Yen-Nakafuji, and Tim Dunn Lawrence

Livermore National Laboratory

Fred Browand and Mustapha Hammache, University of Southern California

Anthony Leonard and Mike Rubel, California Institute of Technology

Walter Rutledge, Chris Roy, and Mary McWherter-Payne, Sandia National Laboratories

Jim Ross, Dale Satran, Bruce Storms, Steve Walker, and J.T. Heineck, NASA Ames Research

Center

\subsection{Activities and Accomplishments}

\subsection{Working Group Meeting}

\section{LLNL in September 2001}

A Working Group Meeting on Heavy Vehicle Aerodynamic Drag was held at Lawrence Livermore National Laboratory on September 13-14, 2001. Team members presented status reports and plans for FY02. DOE representative, Jules Routbort, participated via teleconferencing and provided an update on the budget situation.

Plans for April 2002

A Working group meeting is being organized for April 3-4, 2002 at LLNL that will include participants from industry and other invited guests.

\subsection{ANL Proposal Review}

On September 26, 2001, we held a conference call with the Aero Team and ANL to discuss ANL's proposal for work. Notes from the meeting were constructed and edited by the conference call participants through a series of e-mail correspondence. The resulting report was provided to our DOE representative, Jules Routbort.

\subsection{Working Group Conference Call}

The Team presented summaries of their planned activities and deliverables for FY02 and an update on their progress during a conference call on December 5, 2001.

\subsection{Engineering Foundation Conference}

A document describing a number of journals and magazines that would be relevant to the upcoming aerodynamics conference for advertising purposes was provided to the United Engineering Foundation (UEF). A draft of the general announcement has also been written. It will be sent to UEF within the week.

\subsection{Technical Accomplishments}

Each organization has provided a one-page summary of their recent activities for the start of FY02. Overall, progress has been good and we are well on our way to a successful year in achieving our goals and deliverables. In summary, the near-term deliverables are to provide industry with 
Guidance on the use of computational tools and

Insight into the flow phenomena for the design of low-drag heavy vehicles.

The guidance on computational modeling will be accomplished through the analysis of existing data with comparison to our Reynolds averaged Navier-Stokes (RANS) and large-eddy simulations (LES) and a hybrid method called detached-eddy simulation (DES). An understanding of gap-flow, base drag, frontal flow, and the effect of drag reducing devices will be gained from experimental analysis as well as the validated computations.

\subsection{Future Plans}

As mentioned above, the next Working Group Meeting will be hosted by LLNL April 3-4, 2002. The purpose of this meeting will not only be for the Team to report on their progress and share their findings, but to continue our interactions with industry and to identify areas of possible collaboration. In the interim, the Team will continue to have conference call meetings to share ideas, provide peer review, and keep each other up-to-date on our progress.

Our planning efforts continue for the Engineering Foundation Conference on Aerodynamics of Trucks, Buses, and Rail Cars scheduled for the week of December 2, 2002. 


\section{Lawrence Livermore National Laboratory \\ Quarterly Report}

\section{January 15, 2002}

Activities for this first quarter include continued effort in simulating the experiments performed in the NASA 7 -ft $\mathrm{x}$ 10-ft wind tunnel with the GTS geometry using both LLNL's advanced computational tools and NASA's Overflow code. Along with this analysis effort, we continue to implement advanced algorithms in LLNL's models to improve simulation speed and accuracy and to verify and validate these advanced simulation tools.

\section{Heavy Vehicle Simulations}

Using LLNL's advanced computational tools, simulations of the GTS geometry are in progress. In addition to full-scale simulations, we are also investigating details of the GTS base flow. Figure 1 shows preliminary two-dimensional simulations at the experimental Reynolds number $\left(\operatorname{Re}_{\mathrm{w}}=2.0 \times 10^{6}\right)$ for a medium grid of 25,248 elements. Course grid (6,312 elements) calcuations are also in progress and a fine grid is being generated. These simulations will provide guidance in constructing three-dimensional simulations to follow.

The Overflow code and all its pre and post processing tools (Overflow, Pegsus and Chimera Grid Tools Set) are in place and tested. NASA 7x10 tunnel meshes are constructed and simulations are in progress. One Pentium PC running Linux has been dedicated for running Overflow. Discussions with NASA staff are proceeding to determine the best approach in using the overset techniques and boundary conditions to run Overflow. Planned activities include

Compare results with calibration results from the experiment (planned for completion in February),

Conduct grid refinement studies and compare with experimental calibration results,

Continue work on overset grid with GTS model in tunnel to be ready for runs by late February,

Coordinate LLNL site visit with NASA staff to provide update on changes/usage of overset techniques (late January).

\section{Algorithm Development, Verification, and Validation}

An implicit projection scheme has been successfully implement that has resulted in 1 to 2 orders of magnitude improvement in simulation speed. Verification of this and other model algorithms continues using the method of manufactured solutions. Validation cases for the Blasius flat plate are complete and are in progress for the circular cylinder. Documentation of the algorithms, verification, and validation results are in progress.

To improve simulation accuracy, a van Driest damping function has been implemented in the Smagorinsky turbulence model. The model has been tested for the 2D channel flow.

\section{Documentation of SNL RANS Simulations}

The SNL RANS flow simulations for two grids at $0^{\circ}$ yaw are being documented. Plans are to have this document completed and reviewed and released for distribution to the Team and sponsors next month.

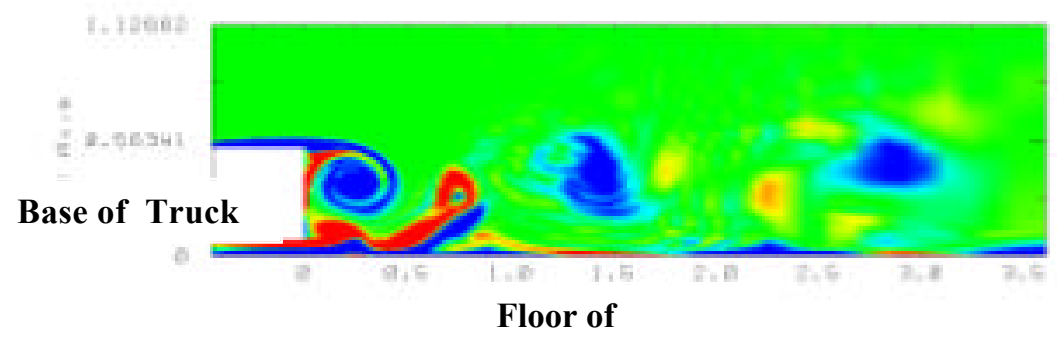

Figure 1. Flow at base of GTS vehicles using large-eddy simulation. 


\title{
Sandia National Laboratories \\ Quarterly Report
}

\author{
January 15, 2002
}

The primary task for this quarter was to perform a wall-normal spacing study to determine required wall $y+$ values for the turbulence models of interest: Spalart-Allmaras, k-epsilon, and the Wilcox k-omega. The two primary questions to answer were 1) what $y+$ values are required to obtain converged solutions and 2) what is the effect of $y+$ on the accuracy of the predictions. In order to perform this study as efficiently as possible, the simulations were performed in two-dimensions only, and the wind tunnel wall and supports were neglected. The baseline wall spacing (both along and normal to the body) was taken from the FY01 medium mesh which was comprised of approximately 12 million mesh cells. This wall spacing is used for Mesh 1. Since the $y+$ values on this mesh were known to locally achieve values as high as ten, four additional grids (Meshes 2 through 5) were generated by retaining the axial spacing around the 2D truck, but halving the wall-normal spacing. The maximum y+ values were thus $10,5,2,1$, and 0.5 for meshes 1 through 5 , respectively. Iterative convergence histories to steady-state are shown in Figure 1 for the Wilcox k-omega model. The three meshes with y+ values of two and below were converged by ten orders of magnitude, while Meshes 1 and 2 (which had larger $y+$ values) did not converge. Although the two coarsest $y+$ meshes did not converge, the surface pressure for all five meshes is shown in Figure 2. It is clear that instabilities are present for the two meshes where the $y+$ values exceeded two. The Spalart-Allmaras and k-epsilon turbulence models were able to achieve converged results on all five meshes; however, the accuracy suffered when the $\mathrm{y}^{+}$ values were larger than one.

The results of this study provided guidance for the generation of a new three-dimensional GTS mesh based on the FY01 medium mesh. This mesh is designed for a $\mathrm{y}^{+}$of approximately 0.2 on the finest mesh ( 20 million cells), and $\mathrm{y}^{+}$ values of approximately 0.4 and 0.8 on the medium ( 2.5 million cells) and coarse (300,000 cells) meshes. The mesh generation will be completed in January 2002 and solutions will be run in the second quarter using the Wilcox k-omega and possibly the k-epsilon model. The coarse and medium meshes will be employed. If time permits, the fine mesh will also be run.

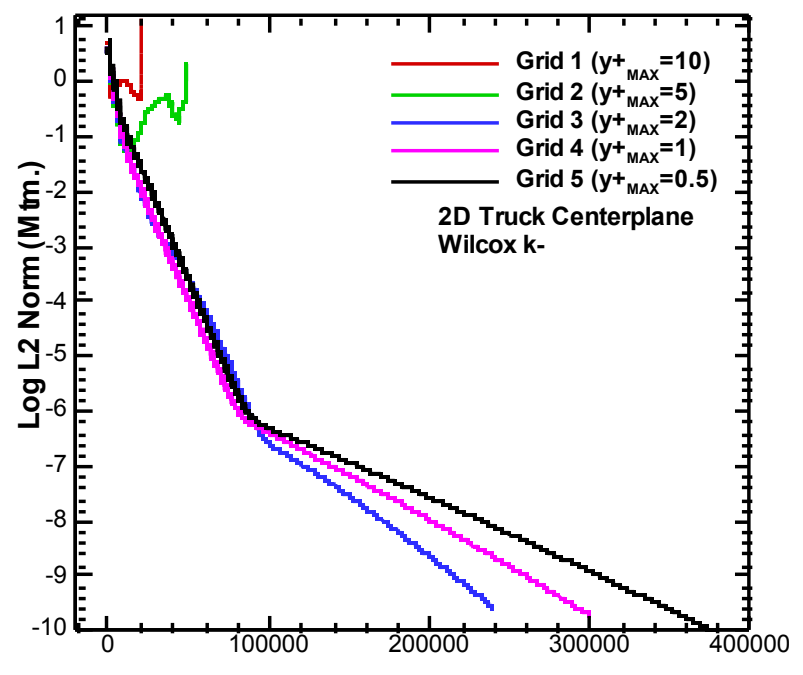

Figure 1

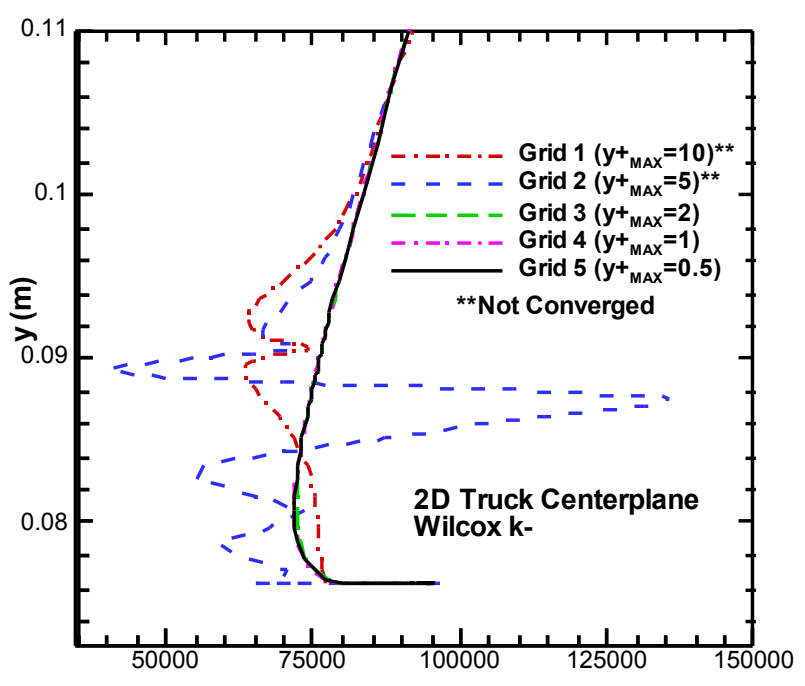

Figure 2 


\section{California Institute of Technology \\ Quarterly Report}

\section{January 15, 2002}

The California Institute of Technology (Caltech) group continues to improve their fast, parallelized, adaptive vortex method. Two of the current tasks are

(1) to develop a vortex filament method that will exactly satisfy the divergence condition for the vorticity field and

(2) to develop a dead-reckoning time integration algorithm to allow efficient time stepping of the vortex method.

For the filament method we have developed a fast tree method for the calculation of the Biot-Savart interaction. Our code is written in Fortran-95 and it is vectorized. We have performed tests calculating with the tree method the propagation of a vortex ring and the results agree with results from the inefficient particle-particle (PP) algorithm. We have calculated and compared also the velocity and pressure spectra of the single ring configuration using both PP and tree methods. The results again agreed with each other. We have incorporated the tree algorithm into an inviscid 3-d vortex-filament code first in infinite domain. Our code (Fortran-95) has the appropriate data structures to treat reconnection.

Our plans for the near future are to incorporate viscous effects, no slip boundary conditions, complex boundary geometry and a subgrid scale model. For the dead-reckoning time integration algorithm the fourth-generation code was completed and run on several different test problems. Unfortunately, the computational speed continues to be limited by oscillations. One new source of oscillations was discovered and corrected: the workload for a single variable ought to taper off as it approaches an asymptote. Our correction gives a marked improvement in the single-variable case, but did not completely eliminate oscillations from the first PDE tests. We will investigate the PDE behavior more carefully in coming weeks. 


\section{NASA Ames Research Center \\ Quarterly Report}

January 15, 2002

\section{Experimental Measurements on Generic Truck Model in 12-ft Pressure Wind Tunnel}

Planning and preparation for experiments in the 12-ft pressure wind tunnel at the NASA Ames Research Center are underway. The flow around a generic conventional model (GCM) (Figure 1) will be documented during a 2- to 3-week entry in the Wind Tunnel. This data will provide a complete data set that includes most of the pertinent flow physics for full-scale trucks. In particular, the effects of Reynolds Number will be examined over a range of approximately 0.1 to 1.2 time fullscale values. The model is the same one tested in the Ames 7- by 10-Foot Wind Tunnel in FY01. Effects of tractor/trailer gap and base-drag reduction devices will be evaluated (including no gap). Data will include tractor, trailer, and base pressures, particle image velocimetry (PIV) in the wake and gap, and oil-flow visualization and skin friction measurements.

\section{Results of FY01 test of GCM in 7-ft x10-ft Wind Tunnel}

Preparation of a NASA Technical Memorandum has begun to document the results of experiments with the GCM geometry in the NASA Ames Research Center 7-ft x 10-ft wind tunnel in FY01. This will include data for 476 pressure taps on the vehicle, 43 static pressure measurements on the tunnel side wall, 14 unsteady pressure measurements, forces and moments for the vehicle, drag and yawing moment for the tractor, and 3D PIV in tractor/trailer gap and wake.

\section{Planned FY'02 Deliverables}

CFD validation data for generic truck geometry at a wide range of Reynolds numbers with preliminary report Effect of Reynolds number documented

Final report on Generic Conventional Model testing in 7- by 10-Foot Wind Tunnel in FY01

Report on analysis of wake data from GTS testing in 7- by 10-Foot Wind Tunnel

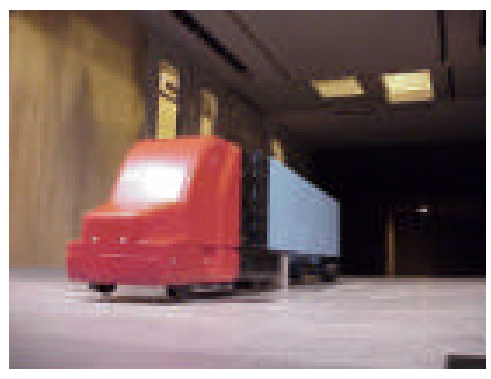

Figure 1. Generic Conventional Model (GCM) in wind tunnel.

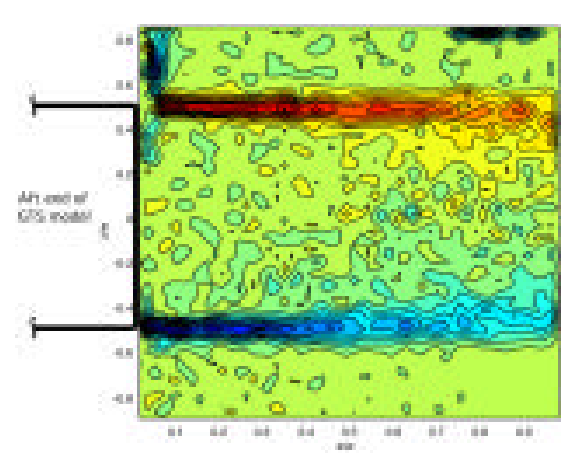

Figure 2a. Baseline geometry.

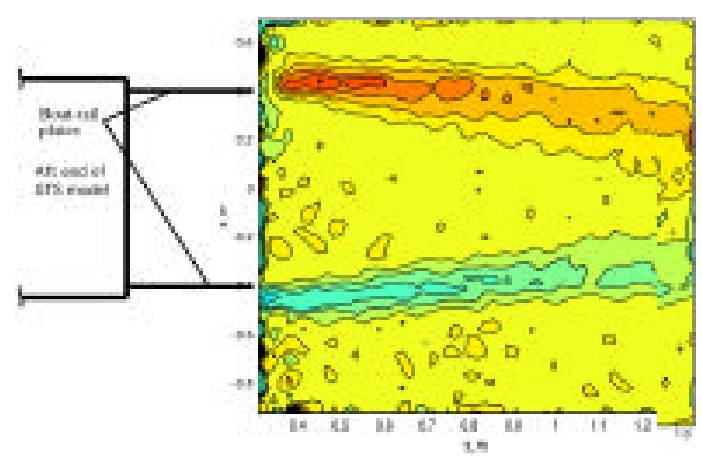

Figure $2 \mathrm{~b}$. With boat-tail plates.

Figure 2. Contours of time-averaged vorticity in horizontal plane in wake of GTS model. 


\section{University of Southern California}

\section{Quarterly Report}

\section{January 15, 2002}

\section{Reporting of FY01 Experiments in NASA Wind Tunnel using USC's Modified GTS Geometry}

Results of experiments in the NASA 7-ft x 10-ft wind tunnel were reported to the Team. The objective of these experiments is to compare the results obtained in the USC wind tunnel using the USC modified GTS geometry to those obtained in the NASA wind tunnel with this same geometry.

The figures below show the results of the NASA tests compared to tests in USC's wind tunnel for the USC modified GTS foam model. The photo at top left shows the model installed in the USC wind tunnel. The USC wind tunnel ground plane has a porous surface, and a very thin boundary layer $-\delta^{*}$ less than $1 \mathrm{~mm}$. The checker-board-patterned area on the ground plane is a shelf paper covering placed in the vicinity of the model to remove the possibility of local flow through the surface while maintaining a generally thin boundary layer. The plot directly below shows corrected drag coefficients for both tunnels as a function of height above boundary layer and Reynolds number. NASA drag measurements are corrected for the drag of the posts (using the post alone runs) and USC's are corrected for blockage. (We presume the value of $q$ given for the NASA tests would be the $q$ at the model location in the wind tunnel. If not, the NASA drag measurement would have to be adjusted.) The red circles are USC's values. Red, blue, green stars and fits are NASA values. We overlap in Reynolds number at the lowest Reynolds number. USC's results are higher, but not greatly so. In addition, USC's results do not show variation with height above boundary layer, but NASA measurements do show dependence on model height.

Plots on right show variation of corrected drag with gap at zero yaw and the blue stars are NASA measurements. The red stars are USC's measurements--many more points. USC measurements have been made using the porous surface and with the porous surface covered. The Reynolds numbers are about the same for the NASA and USC tests, and the height above the boundary is nearly the same.
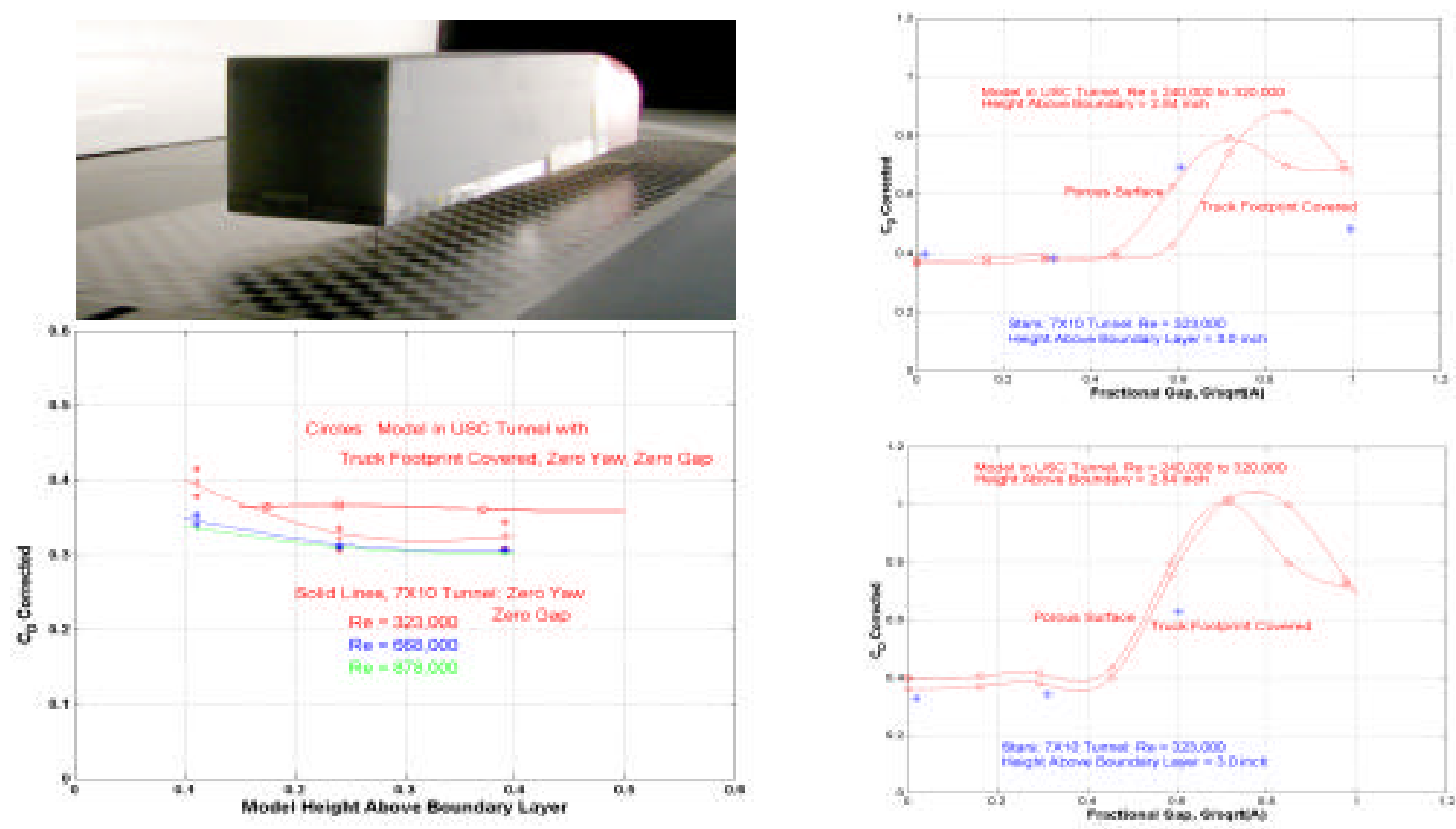